\title{
AUTOMATIC ANALYSIS OF DESCRIPTIVE TEXTS
}

\author{
Jamea R. Cowle \\ Computer Centre \\ Unlversity of Strathclyde, \\ Royal College, George Street, \\ Glasgow, GI 1XW. SCOTLAND
}

\section{ABSTRACT}

Th1. paper describes a system that attampts to Interpret descriptive cexts without the use of complex grammars. The purpose of the system is to transform the descriptions to a standard form wh1ch may be used as the basis of a database system knowledgeable in the subject matter of the text.

The texts currently used axe wild plant descriptions taken directly from a popular book on the subject. Properties such as size, shape and colour are abstracted from the descriptione and related to parts of the plant in which we are incerested. The resulting output is a standardised hierarchical structure holding only s1gnificant features of the description.

The systen, Implemented in the PROLOG programing language, uses keywords to 1dentify the way segments of the text relate to the object described. Information on words is held in a keyword list of nouns relating to parts of the object described. A dictlonary contalns the attributes of ordinary words used by the system to analyse the text. The text 1s divided inco segments using information provided by confunctions and punctuation.

About half the texts processed are correctly analysed at pregent. Proposals are made for future work to fmprove this figure. There seems to be no Inherent reason why the technique cannot be generallsed so that any text of semi-standard descriptions can be automatically converted to a canonical form.

\section{INTRODUCTION}

A lot of useful information, covering many subfect areas, is presently avallable in printed form in catalogues, directories and guides. Good examples are plants in "Collins Pocket Gulde to Wild Flowers", aeroplanes in "Jane's All the World's Aircraft" and people in "Who's Who". Because this information is represented in a stylised form, it is amenable to machine processing to abstract salient details concerning the entity being described. The research described here is part of a long term project to develop a system which can 'read' descriptive text and so become an expert on the material which has baen read.

The first stage of this research is to establish that it is indeed possible to abstract useful informetion from descriptive text and we have chosen as a typical example a text consistlng of descriptions of wild plants. Our system reade this taxt and generates a fomal canonical plant description. Ultimately this will be input to a knowledge-based system which will then be able to answer questions on wild plants.

The papar gives a limited overview of the recent work in text analysis in order to establiah a context for the approach we adopt. An ourline of the operacion of the system is then ande.

The analyois of our text proceeds in four separace stages and these are considered in conjunction with a sample text. The first stage attaches to each word in the text attributes wh1ch are held in elther a keyword list or the system dictionary. Th1s expanded text is then split up using confunctione, punctuation marks and the keywords in the text to assign each segment of the text to a particular part of the plant. The third stage gathers up the descriptions for a particular part and abatracts properties from thew. The final operation formats the output as required.

We then look at the more detalled operation of the system in terms of specific parts of interest. This covers the dictionary, skeleton structures, text splltetng, text analysis and the linited word guessing attempted by the system.

Future developments are then considered. In particular the possibility of generalising the system to handle other copics. The actual implementation of the system and the use of PROLOG are examined and we conclude with some notes on the current utllity of our system.

\section{BACKGROUND}

Many research workers are interested in different aspects of text analysis. Much of the 
emphasis of this work depends on the use of sophisticated grammars to map to the internal representarion. The work done by Schank (1973) and that of Sager (1981) are two contrasting examples of this interest. In addition to the research orfented work, some commercial groups are interested in the practicability of generating database input from text.

Although the internal detalls of the various systems are totally different the final result is some form of layout, script or struccure which has been filled out with details from the cext. The approach of the varlous groups san be contrasted according to how much of the text is preserved at this point and how much additional detail has been added by the system. DeJong (1979) processes newswire stories and once the key elements have been found the rest of the text is abandoned. Sager makes the whole text fit into the layout as here small detalls any be of vital importance to the end user of the processed text. Schank in his gtory understanding programs may actually end up with more information than the original text, supplled from the system's own world knowledge.

The other contrasting factor is the degree of limitation of the domaln of interest of the text processors. The more a system has been designed with a practical end in view, the more limited the domaln. Schank is operating at the level of general language understanding. DeJong is limiting this to the task of news recognition and abscraction, but only certain stories are handled by the system. Sager has reduced the range still furcher to a particular type of medical diagnoses.

Very recent work appears to be approaching text understanding from a word oriented viewpoint. Each word has associaced with it processes which drive the analysis of the text (Sma11, 1981). We have also been encouraged in our own approach by Kelly and Stone's (1979) work on word disamblguation. The implication of which seems to be that word driven rules can resolve ambiguities of meaning in a local context.

Our own case is a purely practical attempt to generate large amounts of database bullding information from single toplc texts. It should not be assumed however that a truly comprehensive syntax for a descriptive text would be simpler chan for other types. The reverse may be true and the author of the descripelons at atempt to liven up his work wich asides, unusual wordorders and additional acmospheric details.

Our system does not use sophisticated grammatical techniques. It is our contention that in the domain of descriptive texts we can make certain assumptions about the way the descriptive data is handled. These allow very crude parsing to be sufficient in most cases.

Similarly the semantic structures Involved are simple. A description of an object consisting of several parts usually mentions the part and its properties in a single piece of text. The basic properties we are looking for - shape, colour, size - are all described by words with a direct physical relation or with a simple mental association. What we are really trying to do is tidy the description into a set of suitable noun phrases.

III OUTLINE OF THE SYSTEM

The text analysis system has been constructed on the assumption that much of the $\mathrm{in}^{-}$ formation held in descriptive texts can be extracted using very simple rules. These rules are analogous to the 'sketchy syntax' suggested by Kelly and Stone and operate on the text on a 10cal rather than a global basis.

At the time of writing our system processes plant descriptions, in search of cen properties which we consider distinctive. Examples of these properties are the size of the plant, the colour of lts flowers and the shape of its flowers. New properties can be added simply by extending the skeleton plant description.

Example 1. A Sample Analysis

SMALL BUGLOSS.

An erect bristly annual, up to a foot high, with wavy lanceolate leaves and smail blue flowers which are the only ones of their family to have their corolla-tube kinked at the base; calyx with lanceolate teeth, hardly enlarging but wuch exceeding the fruit. Habitat: Widespread and locally frequent in open spaces on light soils. April onwards.

$\begin{array}{llll}\text { TOPIC } & \text { COMPONENT } & \text { PROPERTY } & \text { PROPERTY } \\ & \text { PARTS } & \text { NAMES } & \text { VALUES }\end{array}$

plant general name

size

small bugloss a foot high

Elower

leaf

colour

shape

size

shape

size

colour

habitat geog-location widespread season blue

noinfo

small

wavy lanceolate

noinfo

noinfo$$
\text { season }
$$

\section{april onwards}


Figure 1. System Outline

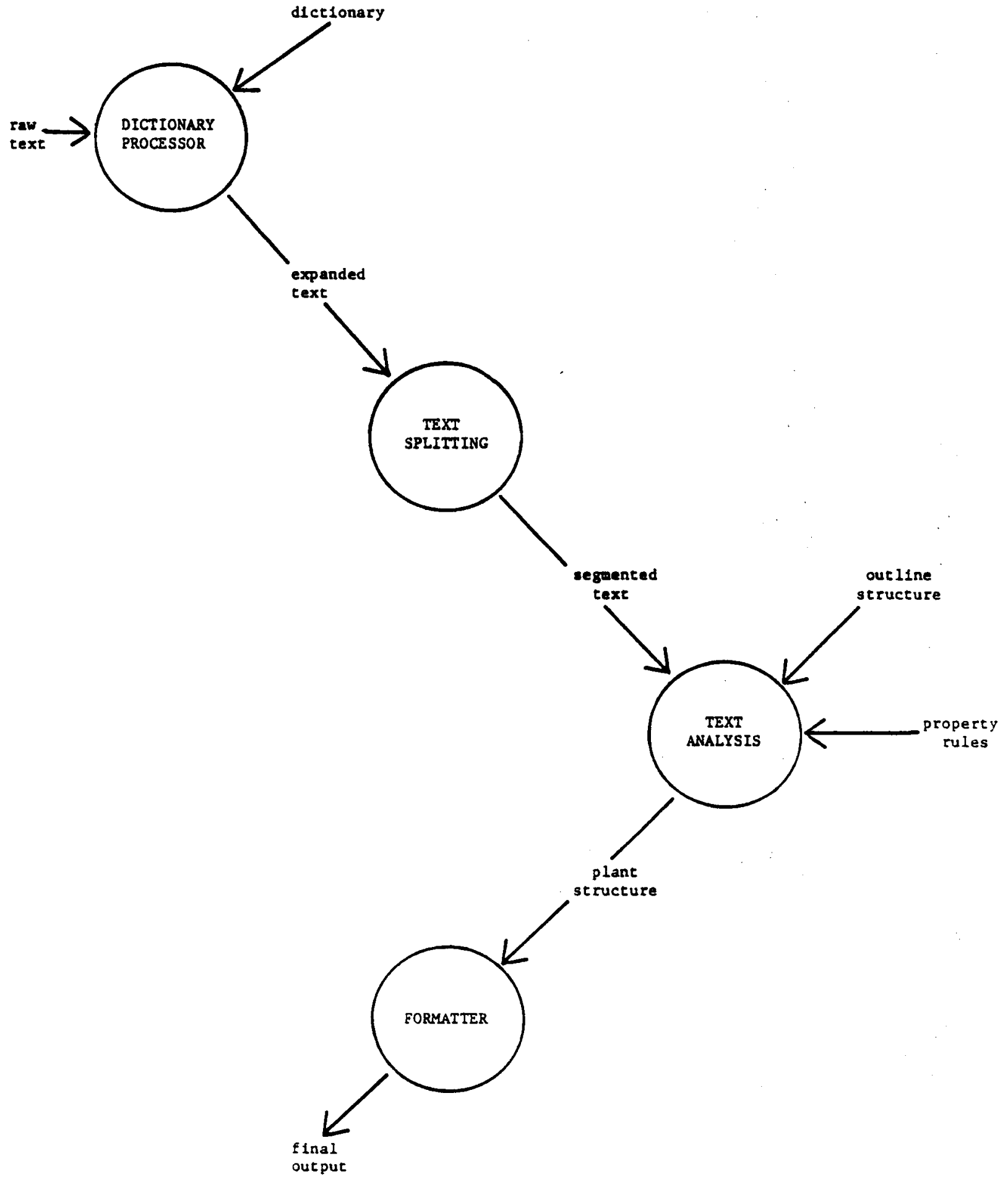


The cexts being processed are plant descriptions as found in McClintock and Fitter $(1974)$. The system has been built to handle this tople and it attempes to fill out varfous properties for selected parts of a plant. A skeleton description is used to drive the processing of the text. This indicates the parts of the plant of interest and the properties required for each part.

The structure which we presently use is shown in Example 1 after it has been filled out by processing the accompanying description. It should be noced that if the system cannot find a property then the null property 'nolnfo' is returned.

An outline of how a description is processed by the system and converted to canonical form is given in Figure 1 . There are four distinct stages in the transformation of the text.

\section{A. Dictlonary processor.}

The raw text is read in and each word in the text is checked in a dictionary/keyword 11st. Each dictionary entry has an assoctaced list of attributes describing both syntactic and semantic attributes of that word. These attributes are looked at in more detail in section IV. If a word in the text appears in the dictionary it is supplemented with an attribute list abstracted from the dictionary.

The keywords for a text depend on which parts of the object we are interested. Thus for a plant we need to include all possible variants of flower (floret, bud) and of leaf (leaflet) and 30 on. Fortunately this is not a large number of words and they can be easily acquired from a thesaurus.

The output from this stage is a list of words and atcached to each word is a list of the attributes of this word.

\section{B. Text splitring.}

The expanded text is then burst into segments associated with each keyword. We Identify segments by using 'pivotal points' in the text. Pivotal points are pronouns, conjuntions, prepositions and punctuation marks. This is the simplifying assumption which we make which allows us to avoid detalled grammars. The actual words and punctuation marks chosen to split the text are critical to the success of this method. It may be necessary to change these for texts by a different author as each author's usage of punctuation is falrly idiosynchracic. Within a given work however faifly consistent results are obtained. The actual splitting of the text is covered more fully in section IV C.

\section{Text analysis.}

We now have many small segments of text each with an attached keyword. This keyword indentifies the cext as describing a particular part of the plant. Text segments are gathered cogether for a particular keyword. This may pull together text from separate parts of the original description

This new unit of text is then examined to see if any of the words or phrases in it satisfy the specific property rules requlred for this part of the plant. If found the phrases are inserted into appropriate parts of the structure.

\section{Formatter.}

The ultimate output of the system is intended as input to a relational database system developed at the University of Strathclyde. At the moment the structure is displayed in a form that allows checking of the system performance.

\section{SYSTEM DETAILS}

\section{A. The Dictionasy}

The dictionary is the source of the meanings of words used during the search for properties. Two other word sources are incorporated in the system, a list of keywords which is specific to the subject being described and a list of words which may be used to split the text. This second list could probably be incorporated in the dictionary, but we have avolded this until the system has been generalised to handle other types of text.

The dictionary entry for each word consists of three lists of attributes. The first contains it's part of speech, a flag lndicating the word carrles no semantic information and some additlonal attributes to control processing. For example the attribute "take-next" indicates that if a property rule is already satisfied when this word is reached in the text then the next word should be attached to the property phrase already found. Thus the word "-" carries this property and pulis in a successive word.

The second list contalns atcributes whose meaning would appear to be expressible as a physical measure of some kind:- "touch-roughness", "vision-intensicy". Many of the words used in descriptions can be adequately categorised by a single attribute of this type. Thus the word ted is an "adjectlve" with a physical property "vision-colour".

The third contains those which require physical measures to be mapped and compared to internal representations or which deal with the manipulation of internal representations alone:"form-shape", "context-location". Words using these attributes generally tend to be more complex and may have multiple attributes. Thus the word field has as attributes "context-location" 
and "relarlonsh1p-multiple-example" whereas the word Scotland also carries "context-locat1on" but is quallfied by "relacionship-single-example".

We realize chis division is delimiced by an extremely fuzzy border, but when the search for a basis for word definition was made this helped the 1ntuitive allocation of atributes. Sixty Iive different attributes have been allocated. Only sixteen of these are used in the rules for our current list of properties.

The size of the dictionary has been conolderably reduced by Including the algorithm, given by Kelly and Stone (1979), for suffix removal in the lookup process.

\section{B. Skeleton Structure}

The structure we who to fill out 18 mapped directly to a hierarchical PROLOG structure with the uninstantiated vartables, shown in the atructure in capital letters, indicating where pleces of text are required. The PROLOG system f111s in these vartables at run tine with the appropriate words from the text. Each varfable in a completed structure should hold a list of word which describe that particular property. Thus a partial plant structure is defined as:-

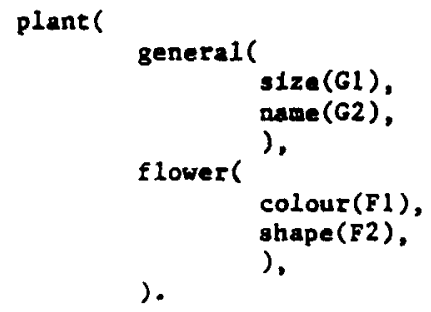

This skeleton is accompanied by a set of keyword lists. Each list being associated with one of the first levels of the structure. Thus a partial llst for 'flower' wight be:-

keyword (f lower, 1$)$. keyword (bud, 1$)$. keyword (petal, 1 ). keyword (floret, 1$)$.

The number indicates which item on the first level of the structure is associated with these keywords.

\section{Text Splitting}

The fundamental assumption we make for descriptions of objects is that the part described will be mentioned within the piece of cext referring to $1 t$. Thus conjunctions and punccuation marks are caken to flag pivotal points in the text where actencion shifts from one part to another.

We assume initially that we are describing the general detalls of the plant, so the text read up to the first pivotal point belongs to that part of our structure, keyword level 0 . Each subsequent plece of text found assigns to the same keyrord unt1l a plece of text is found contalning a new keyword. This becowes the current keyword and following pleces of text belong to this keyword until yet another keyword is found.

\section{Property Rules}

We now gacher togecher the pleces of text for a part of the structure and look for propercles as defined in the skelecon structure. A property search is carried out for each of the property names found at level two of the structure. The property rules have the general form:-

Set 'property' to NO

repeat 1

exanine ateributes of next word

If (sultable nod1fler attributes)

chen keep rord

$1 f$ (sultable property attributes)

then keep word and set 'property' to YES

1f (no sultable atcributes and 'property' is NO)

then throw away any words kept so far

If (no sultable ateributes and 'property' is YES)

then exit repeat

if (no more words)

then exit repeat

if ('property' is YES) then recurn words kept

if ('property' is NO) then return 'noinfo'.

E. Spectal Purpose Rules

We are trying to avold rules spectfically assoclated with layout which would need rederinition for different texts. However the system does assume a certain ordering in the initial title of the descriptions. Thus the name of the plant is any adjectives followed by a word or words not in 
the dictionary. It $1 \mathrm{~s}$ intended to add rules to detect the Latin specific name of the plant. We have excluded these from our current rexts. These w1ll in all probability be based on a similar rule of ignorance, reinforced by some knowledge of permissible suffices.

\section{F. Spec1ally Recognised Words}

Certaln words are identified in the dicclonary by the actributes "take-nexc" and "takeprevious". They imply that if a property rule is sacisfied at the time that word is processed then the successor or predecessor of that word and the word itself should be included in the property. The principal use of this occurs in hyphenated words. These are treated as three words; wordl, hyphen, word2. The hyphen carries both "takenext" and "take-previous" attributes. This of ten allows attachment of unknown words in a property phrage. Thus "chocolate-brown" would be recognised as a colour phrase despite the fact that the word chocolate is not included in the dictlonary.

Words wh1ch actually name the property being sought after carry a "take-previous" attribute. Thus "coloured" when found will pull in the previous word e.g. "butter colour" although the word butter may be unknown or have no specific dictionary attribute recognised by the rule.

\section{FURTHER DEVELOPMENTS}

In the short term, the size of the dictionary and the rules built into the system must be increased so that a higher proportion of descriptions are correctly processed. Another problem which we must handle is the use of qualifiers referring to previous descriptions e.g. 'darker green' or 'much less hairy than the last species'. We intend to cackle this problem by merging the current canonical description with that of plants referred to previously

It would appear from work that has been carried out on dictionary analysis (Amsler, 1981) that a less 1ntultive method of word meaning categorization may be available. If it proves possible to map from a standard dictionary to our set of attributes or some related set then the rigour of out incernal dictionary would be significantly improved and a major area of reperitive work might be removed from the system.

It is also intended to extend the suffix algorithm to handle prefixes and to convert the part of speech attribute according to the transformations carried out on the word. This has not proved. Important to us up to the present but future uses of the dictionary may depend on its being handled correctly.

In the longer term we Intend to generalise the system to cope with other topic areas. In particular, we intend to provide a user interface to allow the system to be modifled for a specific tople by user definitions and examples.

The potential also exists for mapping from our word based internal representation to a more abstract machine manipulable form. This may be the most interesting direction in which the work will lead.

\section{IMPLEMENTATION}

The code for the system is written in PROLOG (Clocksin and Mellish, 1981) as implemenced on the Edinburgh Multi Access System (Byrd,1981). This is a standard implementacion of the language, with the single enhancement of a second incernal database which is accessed using a hashing algorithm rather than a linear search. This has been used to 1oprove the efficlency of the dictionary search procedures.

PROLOG was chosen as an implementation language mainly because of the ease of manipulation of structures, I1sts and rules. The skeleton plant and keyword insts are held as facts in the PROLOG database. The implementation of the suffix stripping algorithm is a good example of the ease of expressing algorithms in PROLOG. The mapping from the original to our code being almost one to one.

In addition the Implementation on EMAS allows large PROLOG programs to be run. The interpretive nature of the language also means that trace debugging facilfties are avaflable and new pieces of code can be easily incorporated into the system.

\section{CONCLUSIONS}

Initial indications suggest that for about $50 \%$ of descriptions, all ten properties are correctly evaluated and for about $30 \%, 8$ or 9 properties are correct. The remaining $20 \%$ are unacceptable as less than 8 properties are correctly determined by the system.

We anticipate that increasing the knowledge base of the system will significantly increase its aceuracy.

The very primitive 'sketchy syntax' approach appears to offer practical solutions in analysing descriptive texts. Furthermore, there seems to be no intrinsic reason why a similar method could not be used to analyse temporal or causal structures. There will always be segments of text that the system cannot cope with and to achieve a greater degree of accuracy we will need to allow the system to consult with the user in resolving difficult pieces of text. 
The structured nature of the system output allows the possibllity of bullding a complex database system. A data base system based on the raw text alone has no abilicy to distingulsh to which part of an object any property belongs as its searches are made on the basis of keywords alone without taking contextual information into account.

VIII ACKNOWLEDGEMENTS

\begin{abstract}
I would like to thank the director of the Computer Centre Mr. Grant Fraser for mak1ng available time to carry out this work and my supervisor Dr. Ian Sommerville for his help in the development of the system and in the writing of this paper.
\end{abstract}

\title{
IX REFERENCES
}

Amsler, Robert A. A Taxonomy for English Nouns and Verbe. Proc. 19th Annual ACL, 1981, 133-138.

Byrd, Lawrence, ed. A User's Gulde to EMAS PROLOG. D.A.I. OccasionaI Paper No. 26. Department of A.I. EdInburgh University, 1981.

Clocks1n, W1111am F. and Christopher S. Mellish. Programming in PROLOG. Heldelberg: SpringerVeriag, 1981

DeJong, Gerald F. Sk1mming Stories in Real Time. Research Report 158. Department of Computer Sc1ence, Yale University, 1979.

Kelly E. and P. Stone. Computer Recognition of English Word Senses. Ansterdam: North-Holland, 1979.

McClintock, David and R.S.R. FItter. The Collins Pocket Guide to W1ld Flowers. London: Collins, 1975.

Sager, Naom1. Natural Language Information Process1ng. Reading, Mass.: Add1son-Wesley, 1981 .

Schank, Roger C. and Kenneth M. Colby, eds. Computer Models of Thought and Language. San Francisco: Freeman, 1973 . 